\title{
Comunicação
}

[Communication $]$

\section{Qualidade de méis produzidos por apicultores e méis provenientes de entrepostos registrados no Serviço de Inspeção Federal}

[Quality of honeys produced by beekeepers and honey from warehouses registered at the Federal Inspection Service]

\author{
M.B.L. Silva ${ }^{1}$, J.B.P. Chaves $^{2}$, M.E.R. Valente ${ }^{2}$, J.C. Gomes ${ }^{2}$, G.F. Oliveira ${ }^{2}$, D. Message ${ }^{2}$ \\ ${ }^{1}$ Departamento de Agroindústria - Instituto Federal doTriângulo Mineiro - Campus Uberaba \\ Rua João Batista Ribeiro, 4.000 - Mercês \\ 38064-790 - Uberaba, MG \\ ${ }^{2}$ Universidade Federal de Viçosa - Viçosa, MG
}

O Brasil tem um grande potencial apícola, por possuir flora bastante diversificada, vasta extensão territorial e variabilidade climática, o que possibilita produzir mel o ano todo, e o diferencia dos demais países que normalmente colhem mel uma vez por ano (Marchini et al., 2001).

No campo, o controle da qualidade deve iniciar no manejo das colméias, indo desde a escolha do local do apiário até a extração na casa do mel. A composição do mel depende, basicamente, dos componentes do néctar da espécie vegetal produtora que conferem ao produto características específicas. Já a influência das condições climáticas e do manjeo do apicultor é menor, embora exerçam efeito sobre as características físico-químicas do produto (Marchini et al., 2001). Após a colheita, o mel continua sofrendo modificações físico-químicas, microbiológicas e sensoriais. Isto gera a necessidade de produzi-lo dentro de padrões elevados de qualidade, controlando todas as etapas do seu processamento, afim de que se possa garantir um produto de qualidade (Araújo et al., 2006).

As análises físico-químicas exercem papel importante na fiscalização de méis importados e no controle da qualidade do mel produzido internamente. Os resultados são comparados com os padrões oficiais internacionais e com os estabelecidos pelo próprio País, com a finalidade de proteger o consumidor em não adquirir um produto adulterado ou de baixa qualidade (Marchini, 2004). A avaliação físico-química dos constituintes do mel é necessária, uma vez que estes influenciam a qualidade durante a estocagem, a cristalização, a textura, o aroma e a qualidade nutricional (Joshi et al., 2000).

O desconhecimento das noções de qualidade no setor tem acarretado uma forte insuficiência de qualificação da mão de obra, em conseqüência, muitos apicultores não conseguem obter o selo do Serviço de Inspeção Federal (SIF) em razão das inadequações da infra-estrutura física ou instalações para a realização do beneficiamento do mel. O presente trabalho desenvolveu-se com o objetivo de avaliar as qualidades físicoquímicas dos méis.

As análises foram realizadas em amostras de méis provenientes da produção de 13 apicultores da região Norte da Zona da Mata Mineira e de seis marcas de méis com registro no SIF, no estado de Minas Gerais. Da produção de cada um dos 13 apicultores obtiveram-se três amostras de mel, $350 \mathrm{~g}$ cada, colhidas em três diferentes dias, durante os meses de maio a julho de 2006, perfazendo um total de 39 amostras. Elas foram armazenadas em embalagens plásticas transparentes com tampas rosqueáveis utilizadas usualmente na comercialização do mel.

Recebido em 22 de outubro de 2010

Aceito em 8 de junho de 2011

E-mail: mariana@iftm.edu.br 
Amostras de seis marcas de mel registrados no SIF foram doadas pelos entrepostos e foram provenientes de diversas regiões do estado de Minas Gerais. Foi obtida uma amostra de mel de $500 \mathrm{~g}$ de cada um de três lotes distintos de produção para cada uma das seis marcas, num total de 18 amostras.

Foram realizadas as análises indicadas pela Instrução Normativa $\mathrm{n}^{\circ} 11$, de 20 de outubro de 2000 do Ministério da Agricultura, Pecuária e Abastecimento (MAPA), que aprova o Regulamento Técnico de Identidade e Qualidade do Mel (Brasil, 2000), para as amostras de méis produzidas por pequenos apicultores e provenientes de entrepostos registrados no SIF, MG.
Acidez livre (método n962.19), hidroximetilfurfural (método quantitativo $\mathrm{n}^{\circ}$ 980.23) e umidade por refratometria (método $\mathrm{n}^{\circ}$ 69.38b) foram determinados segundo AOAC (Official...,1998), e açúcares redutores (item 7.1), cinzas - modificado pela adição de areia (item 7.5) - atividade diastásica (item 7.7), sacarose aparente (item 7.2) e sólidos insolúveis em água (item 7.4) foram determinados segundo CAC (Official..., 1990).

Os resultados de cada um dos indicadores de qualidade dos méis produzidos pelos apicultores e dos méis dos entrepostos com registro no SIF foram comparados entre si e também com os limites estabelecidos pela Instrução Normativa $\mathrm{n}^{\circ} 11$, do MAPA (Brasil, 2000) (Tab. 1).

Tabela 1. Médias e desvios-padrão das análises físico-químicas de amostras de méis produzidos por pequenos apicultores, méis de entrepostos com registro no SIF-MG e valor estabelecido pela Instrução Normativa $n^{\circ} 11$ de 2000 do MAPA ${ }^{1}$

\begin{tabular}{|c|c|c|c|}
\hline Analisada & Mel (apicultores) & Mel (SIF- MG) & Instrução $n^{\circ} 11 *$ \\
\hline Acidez livre (meq/kg) & $34,50 \pm 3,30$ & $31,30 \pm 1,60$ & $\max .50,00$ \\
\hline Açúcares redutores $(\%)$ & $68,40 \pm 1,40$ & $66,90 \pm 1,20$ & $\min .65,00$ \\
\hline Cinzas $(\%)$ & $0,155 \pm 0,035$ & $0,119 \pm 0,070$ & $\max .0,600$ \\
\hline Hidroximetilfurfural (mg/kg) & $7,63 \pm 3,30$ & $5,14 \pm 3,10$ & $\max .60,00$ \\
\hline Índice de diastase (DN) & $16,60 \pm 2,30$ & $15,30 \pm 3,50$ & $\min .8,00$ \\
\hline Sacarose aparente $(\%)$ & $4,00 \pm 0,80$ & $3,20 \pm 0,70$ & $\max .6,00$ \\
\hline Sólidos insolúveis (\%) & $0,084 \pm 0,050$ & $0,070 \pm 0,030$ & $\max .0,10$ \\
\hline Umidade $(\%)$ & $17,80 \pm 0,45$ & $17,30 \pm 0,20$ & $\max .20,00$ \\
\hline
\end{tabular}

*Basil (2000)

Os resultados das análises físico-químicas dos méis produzidos diferiram, positivamente, dos limites estabelecidos pela Instrução Normativa n¹1 do MAPA. Açúcares redutores, cinzas, hidroximetilfurfural, índice de diástase, sacarose aparente e umidade não apresentaram valores acima do estabelecido pela legislação vigente para nenhuma das amostras individuais analisadas. Contudo, para acidez livre e teor de sólidos insolúveis, algumas amostras apresentaram valores acima do estabelecido pela Instrução Normativa $n^{\circ} 11$ do MAPA.

Houve diferença de qualidade entre méis produzidos por pequenos apicultores e méis de entrepostos com registro no SIF-MG para: acidez livre, cinzas, hidroximetilfurfural, sacarose aparente e sólidos insolúveis.

Os valores de acidez livre estão próximos aos encontrados por Marchini et al. (2001), que constataram valores médios de acidez livre de
$33,80 \mathrm{meq} / \mathrm{kg}$ para méis de eucaliptos e de 30,10 $\mathrm{meq} / \mathrm{kg}$ para méis silvestres. Komatsu et al. (2002) encontraram valor médio de $72,4 \%$ de açúcares redutores em méis oriundos do estado de São Paulo, e Marchini (2004) obteve 74,3\% em méis produzidos no estado de Tocantins. Silva et al. (2005) encontraram valor de cinzas de $0,180 \%$ em amostras produzidas no estado da Paraíba.

De acordo com Dayrel e Vital (1991), os méis de países tropicais podem ter, naturalmente, alto conteúdo de hidroximetilfurfural sem que o mel tenha sido aquecido ou adulterado, e isso é influência da temperatura ambiental mais elevada.

Para Silva et al. (2004), o valor de índice de diastase foi de 15,90 Gothe em amostras oriundas do estado do Piauí, e para Melo et al. (2003), 16,00 Gothe, em méis comercializados em Campina Grande, PB. Rodrigues (2000) 
verificou valor de $0,010 \%$ de sólidos insolúveis em amostras da Paraíba, resultado menor que o encontrado neste estudo, enquanto Araújo et al. (2006) obtiveram $0,120 \%$ em méis comercializados na cidade do Crato, CE.

Quinze amostras não se encontravam de acordo com o estabelecido na Instrução Normativa $n^{\circ} 11$ de 2000 do MAPA, para acidez livre e sólidos insolúveis. Desse modo, recomendam-se mudanças tanto nos apiários quanto nos entrepostos para que haja a garantia da qualidade do mel produzido e processado.

Palavras-chave: mel, apicultura, qualidade

\begin{abstract}
This study was carried out to compare the physiochemical quality of honeys from beekeepers in northern Zona da Mata, MG, and honeys from warehouses registered at the Serviço de Inspeção Federal (SIF) in the State of Minas Gerais. Physiochemical analysis involving 39 samples were done, with three samples from each of the 13 beekeepers and 18 samples from warehouses registered at SIF-MG. Differences in quality from the two origins occurred in: free acidity, ashes, hydroxymethylfurfural, apparent sucrose and insoluble solids, where honeys from warehouses were of better quality. In addition, for free acidity and insoluble solids, two samples from northern Zona da Mata showed values above the established by the Instrução Normativa $\mathrm{n}^{\circ} 11$ relative to the year 2000, whereas the values for insoluble solids in 11 samples from northern Zona da Mata and 2 samples from warehouses were in disagreement with this legislation.
\end{abstract}

Keywords: honey, apiculture, quality

\section{REFERÊNCIAS BIBLIOGRÁFICAS}

ARAÚJO, D.R.; SILVA, R.H.D.; SOUSA, J.S. Avaliação da qualidade físico-química do mel comercializado na cidade de Crato, CE. Rev. Biol. Cienc. Terra, v.6, p.51-55, 2006.

BRASIL. Ministério da Agricultura, Pecuária e Abastecimento. Instrução Normativa $n^{\circ} 11$ de 20 de outubro de 2000. Aprova o Regulamento Técnico de Identidade e Qualidade do Mel. Diário Oficial da União, Brasília, DF, 23 de outubro de 2000.

DAYRELL, I.O.; VITAL, N.C. Comparação entre dois métodos oficiais para determinação de hidroximetilfurfural (HMF) em mel brasileiro. Cienc. Tecnol. Aliment., v.11, p.137-141, 1991.

JOSHI, S.R.; PECCHACKER, H.; WILLIAM, A. et al. Physico-chemical characteristics of Apis dorsata, A. cerana and A. mellifera honey from Chitwan district, central Nepal. Apidologie, v.31, p.367-375, 2000 .

KOMATSU, S.S.; MARCHINI, L.C.; MORETI, A.C.C. Análises físico-químicas de amostras de méis de flores silvestres, de eucalipto e de laranjeira, produzidos por Apis mellifera L., 1758 (Hymenoptera, Apidae) no Estado de São Paulo. 2. conteúdo de açúcares e de proteína. Cienc. Tecnol. Aliment., v.22, p.143-146, 2002.

MARCHINI, L.C.; MORETI, A.C.C.; SILVEIRA NETO, S. Características físico-químicas de amostras de mel e desenvolvimento de enxames de Apis mellifera L., 1758 (Hymenoptera, Apidae), em cinco diferentes espécies de eucaliptos. Bol. CEPPA, v.21, p.193-206, 2001.
MARCHINI, L.C. Composição físico-química de amostras de méis de Apis mellifera L. do estado de Tocantins, Brasil. Bol. Ind. Anim., v.61, p.101-114, 2004.

MELO, Z.F.N.; DUARTE, M.E.M.; MATA, M.E.R. Estudo das alterações do hidroximetilfurfural e da atividade diastásica em méis de abelha em diferentes condições de armazenamento. Rev. Bras. Prod. Agroind., v.5, p.89-99, 2003.

OFFICIAL Methods of Analysis of AOAC International. Arlington: AOAC International. suppl.2, 1998. 1456p.

OFFICIAL methods of analysis of Codex Alimentarius Commission. Roma: FAO, suppl. 2, 1990.

RODRIGUES, A.E. Análise físico-química de méis das abelhas Apis mellifera e Melipona scutellaris. 2000. 50f. Trabalho de Conclusão de Curso (Graduação em Zootecnia) - Universidade Federal da Paraíba, João Pessoa, PB.

SILVA，C.L.; QUEIROZ，A.J.M.; FIGUEIREDO, R.M.F. Caracterização físico-química de méis produzidos no estado do Piauí para diferentes floradas. Rev. Bras. Eng. Agric. Ambient., v.8, p.260-265, 2004.

SILVA, M.S.; BEZERRA, E.M.F.; RODRIGUES, M.L. Análise físico-química dos méis das abelhas Apis mellifera e Melipona scutellaris produzidos em duas regiões no Estado da Paraíba. Cien. Rural, v.35, p.1166-1171, 2005. 